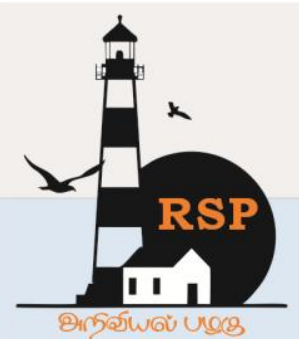

INTERNATIONAL RESEARCH JOURNAL ON ADVANCED SCIENCE HUB

\title{
Case Study on Performing Indoor Gardening with New Technology Implication to Overcome the Gaps in the Existing Solutions
}

Prince Reynold $P^{1}$, Pratheep $C^{2}$, Mark Romario Williams $M^{3}$,NithinGnanam $R^{4}$,Mohamed Ariffuddeen $M^{5}$ ${ }^{1,2,3,4}$ Student, Department of Mechanical Engineering, SNS College of Technology, Coimbatore-641035, Tamilnadu, India.

${ }^{5}$ Associate Professor, Department of Mechanical Engineering, SNS College of Technology, Coimbatore641035, Tamilnadu, India.

reyprince10@gmail.com ${ }^{1}$, arif12md07@gmail.com ${ }^{5}$

\begin{abstract}
In the present-day world, innovation is commanding characteristic things and people aren't in bond with nature. One fundamental issue in this aggregate issue is the inaccessibility of natural foods grown from the ground. In any event, when individuals want to develop natural vegetables, they are in the absence of room at their clogged habitations. In any event, developing it in pots turns into a monotonous procedure because of the prerequisite of successive checking of the plants. Indoor Gardening is a convenient solution for this situation. This paper reviews the benefits and requirements of indoor gardening, and the existing technologies which help urban people practice the art of gardening within their household, office space, or any other closed landscapes, without access to direct sunlight or soil.
\end{abstract}

\section{Keywords: Indoor Gardening, Smart Gardening, Growth light, Automated Gardening}

\section{Introduction}

Gardening is an art involving the growing of plants, especially ornamental plants, including but not limited to flowering plants and crotons. It not only provides fresh oxygen-rich air to the environment but also helps to maintain a peaceful and calm atmosphere that soothes the soul. But, due to the rapid urbanization, most people cannot afford to find a proper place to maintain a garden in front of their houses, and people in apartments could not even have a rooftop garden. Indoor gardening comes in handy in these situations to help aid people in these situations to have a garden of their own. Indoor gardening is the term used to refer to this art practiced within one's house or office or other buildings with or without direct sunlight. Probably the least difficult type of indoor gardening is compartment planting. In this circumstance, any compartment equipped for holding soil, dampness, and plants can be utilized. Pots are the most well-known, however, homesteaders and those looking to upcycle waste may utilize anything from cardboard egg containers to espresso jars. Another case of indoor cultivating is aquaculture planting. Aqua-farming cultivating utilizes no dirt by any stretch of the imagination. Rather, it depends on developing plants in water (generally joined to a skimming substrate), and the utilization of added substances to give the supplements that would originate from the dirt if the plants were developed outside. Indoor cultivating can be little in scale and done by the normal mortgage holder, or it tends to be mechanical in scale and happen in monstrous nurseries. Remember that, regardless of whether it happens inside or outside, all strategies for cultivating expect access to the availability of sunlight, monitoring of the level of water, etc. This paper reviews the benefits of indoor gardening and 
www.rspsciencehub.com

the necessary conditions to ensure the health of the plants.

\section{Literature Review}

The photoautotrophic nature and the physiological changes which happen during different lighting conditions were studied and reported in this journal by Kami et. al. [1]. The endogenous development of the plant due to interaction with the environment and parameters such as light, water, nutrients, etc are studied. These flagging parts incorporate the red/far-red light receptors, phytochromes, at any rate, one blue light receptor, and negative administrative qualities (DET, COP, and FUS) that demonstrate downstream from the photoreceptors in the core. Also, a steroid hormone, brassinolide, likewise assume a job in light-controlled turn of events and quality articulation in Arabidopsis [2]. The role of UV light and blue light in the growth and development of plants was studied by Jenkins, G.I., et.al. [3]. Plant stimulus under various light conditions was studied and has been proved that a tree shade slows down the growth rate of plants by De Frenne, P., et.al. [4]. The growth of plants concerning the time for which they are exposed to light were studied by Jackson, S.D., et.al.[5]. The effect of growth light on the process of photosynthesis of plants, by Tikkanen, M., et.al. gives a detailed account of the impact of growth light on indoor plants. [6]. The effect of near infrared light on the growth of plants and trees, studied by Wang, Y., et.al proved that near infra-red light accelerates the growth of plants by around 67\%[7].

Gardening improveswellbeing and personal satisfaction, physical quality, strength and adaptability, intellectual capacity, and social conductto a great extent [8]. In particular, the indoor garden can improve the quality of air by filtering out harmful substances and in this manner lessening the danger of medical issues for air unsettling influences, as well as chronic head and eye irritation. Biological studies have shown that contact with plants improves one's mental health and productivity levels, and also suggests that it also improves our levels of sensitivity and empathy [9]. Also, there has been growing concern about food safety these days among homeowners. Remodeling an indoor garden can provide new
Volume 02 Issue 08 August 2020

kitchen ingredients reducing the risk of chemical exposure $[10,11]$.

To design a positive domain for indoor cultivating, there are a few elements to think about, for example, presentation to daylight, dampness seepage, height, the distinction among day and night temperatures, and nearness to warm warmth mass. This paper summed up three central points of those generally basic to their endurance that must be considered in structuring a savvy indoor planting framework: light, temperature, and mugginess.

To make the conditions favorablefor indoor cultivating, there are numerous elements to consider like the presentation to light, wetness voidance, rise, the differentiation among day and night temperatures, and vicinity to warm warmth mass. This paper sums up 3 central points of these generally urgent to their endurance that got the opportunity to be pondered in arranging an astute indoor cultivating framework: light-weight, temperature, and wetness.

Predominantly, light is crucial for any plant to photosynthesize to survive. Plants have photoreceptors that assimilate explicit frequencies of daylight from the sun. Most plants perform best with 14-16 h of sunshine or mimicked lightweight. In this way, regardless of whether it's common or reenacted light-weight, enough amount of daylight must be made sure about for ideal indoor cultivating. The impact of temperature plays the second most important role. They considerably influence the 2 processes of chemical action that plants use greenhouse emission to provide element and use oxygen to provide greenhouse emission successively, that is directly connected with overall health and survival of them. The temperatures of 18-23 ${ }^{\circ} \mathrm{C}$ are best for many plants. Third, an absence of wetness within the indoor setting, is a challenge to most plants. However, different planting materials need a distinct quantity of wetness in air and soil. There must be a bespoken water system that supported the varied water consumption of the plants. Last, greenhouse emission (CO2) is usually called the first staple used by plants to provide the natural issue out of that they build their tissues. The outcome of advancing the air with carbon dioxide is that plant 
www.rspsciencehub.com

development and advancement is expanded.In the opposite approach, a high level of carbon dioxide within the air is harmful to humans. Therefore, knowing the carbon dioxide is extremely necessary each for plants and residents to produce and manage the optimum state of an interior setting [11-13].

\section{Existing Solution}

\subsection{Patents}

In 2006, Bissonnette et al. designed an indoor gardening apparatus exclusively for the hydroponic system of gardening [14]. In 2009, Bissonnette et al. designed an indoor gardening system for soil and soil-less methods including hydroponic and aeroponic methods [15]. In 2016 Lepp et al. designed an indoor gardening apparatus, patented in the name of "Indoor Planter" [16]. In 2018, Adams et al. patented their innovation on an indoor gardening system which uses a UV lighting system to help photosynthesis [19].

\subsection{Existing Products}

\subsubsection{Click and Grow}

Click and Grow was started in 2009, by Mattias Lepp, as a solution to indoor gardening aspirants. It makes use of LED lights and specially designed plant pods. The shortcomings of this solution include; blackening of leaves as the plants gain height and touch the LEDs. Adding side arms to raise the plant height manually, is not efficient. Users get confused, as to the correct time for harvest (indoor fruits and vegetables mature fully at a small size). The cost of seed pods is very high. LED lights are harmful to the eyes. Trimming the plant is difficult. Refilling the water at different stages of plant growth, eg. older plants demand more water is a herculean task [16 -18].

\subsubsection{Farmshelf}

Farmshelf is one of the indoor gardening solutions for growing herbs. It employs the hydroponic method to grow crops. The disadvantages of this system include; the need for more maintenance and time. It is too large for a
Volume 02 Issue 08 August 2020

household. Only herbs are grown. Without soil to support, plant death occurs if the system fails.

\subsubsection{Citycrop}

Citycrop is a vertical gardening system. It is another system that works on the hydroponic method for growing crops. Its disadvantages include; vulnerability to power outages. High initial expenses. The nutrient requirement for the plants in hydroponics needs frequent replenishment. Drainage of used water/ Recycling water is laborious.

\section{Discussions}

Indoor gardening systemsare mainly for all types of growers who cannot grow their desirable plants and vegetables on a large scale. The process of indoor gardening requires meticulous care, as the requirements are to be met with at most perfection for the good health of the plants. The above-mentioned Indoor Gardening Appliances provide us with a good opportunity for growing plants in our households as per the requirements. However, a few improvements can be made to facilitate better care for the plants. Automatic height adjustment of the system can prevent the blackening of the leaves due to over-exposure to the heat produced by the light. A water level monitor can be added to help the user to maintain the required level of water in the system. Growth Lights of suitable wavelength may be used in place of LEDs for proper nourishment of the plants. Also, a mobile application can be created to keep the user updated on the status of the system.

\section{Conclusion}

Gardening in general has its physical as well as psychological benefits. It not only provides us with fresh oxygen but also brings peace to our soul while growing herbs and other edible plants provide us with other useful products as well. People living in urban spaces often find it hard to grow plants. The most fundamental issues they face are finding time to take care of these plants and the unavailability of space required to grow them. These indoor gardening systems provide them the space required and make the process of gardening into a much simpler and less time- 


\section{www.rspsciencehub.com}

consuming activity. They createa virtualenvironment for the growth of plants by the urban people who could only dream of growing their desired plants and vegetables in their respective houses and workplaces. Thus, these systems provide a good way to achieve the dream of including a garden in our busy urban lifestyle.

\section{References \\ Journals}

[1] Kami, C., Lorrain, S., Hornitschek, P., and Fankhauser, C., 2010. Light-regulated plant growth and development. In Current topics in developmental biology (Vol. 91, pp. 2966). Academic Press.

[2] Chory, J., Chatterjee, M., Cook, R.K., Elich, T., Fankhauser, C., Li, J., Nagpal, P., Neff, M., Pepper, A., Poole, D. and Reed, J., 1996. From seed germination to flowering, light controls plant development via the pigment phytochrome. Proceedings of the National Academy of Sciences, 93(22), pp.12066-12071.

[3] Jenkins, G.I., Christie, J.M., Fuglevand, G., Long, J.C., and Jackson, J.A., 1995. Plant responses to UV and blue light: biochemical and genetic approaches. Plant Science, 112(2), pp.117-138.

[4] De Frenne, P., Rodríguez-Sánchez, F., De Schrijver, A., Coomes, D.A., Hermy, M., Vangansbeke, P. and Verheyen, K., 2015. Light accelerates plant responses to warming. Nature Plants, 1(9), p.15110.

[5] Jackson, S.D., 2009. Plant responses to photoperiod. New Phytologist, 181(3), pp.517-531.

[6] Tikkanen, M., Grieco, M., Nurmi, M., Rantala, M., Suorsa, M., and Aro, E.M., 2012. Regulation of the photosynthetic apparatus under fluctuating growth light. Philosophical Transactions of the Royal Society B: Biological Sciences, 367(1608), pp.3486-3493.

[7] Wang, Y., Zhang, H., Zhao, B., and Yuan, X., 2001. Improved growth of Artemisia annua L hairy roots and artemisinin production under red light conditions. Biotechnology Letters, 23(23), pp.19711973.

[8] Tse, M.M.Y., 2010. Therapeutic effects of an indoor gardening programme for older
Volume 02 Issue 08 August 2020

people living in nursing homes. Journal of clinical nursing.

[9] Wang, D. and MacMillan, T., 2013. The benefits of gardening for older adults: a systematic review of the literature. Activities, Adaptation \& Aging, 37(2), pp.153-181.

[10] Lee, Y. and Kim, S., 2008. Effects of indoor gardening on sleep, agitation, and cognition in dementia patients - a pilot study. International Journal of Geriatric Psychiatry, 23(5), pp.485-489.

[11] Min, B. and Park, S.J., 2017. A smart indoor gardening system using IoT technology. In Advances in Computer Science and Ubiquitous Computing (pp. 683-687). Springer, Singapore.

[12] Elam, T.R., Everyone can grow! A curriculum to bring nature indoors. (book)

[13] Gardening Under Lights: The Complete Guide for Indoor Growers By Leslie F. Halleck 2018.

[14] Bissonnette, W., Wainwright, R., Payne, C., Thompson, J., Morgan, C. and Bernstein, S., AeroGrow International Inc, 2006. Smart garden devices and methods for growing plants. U.S. Patent Application 11/455,364.

[15] Bissonnette, W.M., Pardikes, B., Robertson, T., Rogers, C., Thompson, J. and Bernstein, S., AeroGrow International Inc, 2009. Indoor gardening appliance. U.S. Patent Application 29/292,564.

[16] Lepp, M., Engwall, S., Pråme, M., Emme, N.P., Hansen, M. and Liiv, T., Oue Click \& Glow, 2016. Indoor planter. U.S. Patent Application 29/483,508.

[17] Lepp, M. and Pedastsaar, P., Oue Click \& Grow, 2016. Method for producing plant growing substrate and plant growing substrate. U.S. Patent Application $15 / 143,638$.

[18] Lepp, M. and Pedastsaar, P., Oue Click \& Grow, 2018. System for indoor plant cultivation. U.S. Patent 10,104,846.

[19] Adams, V. and Adams, Q., 2018.Indoor Gardening System. U.S. Patent Application $15 / 855,766$ 